\title{
Vorwort.
}

Bei dem besonders vor einigen Jahren noch viel stärker als heute sich bemerkbar machenden immer weiteren Vorwärtsschreiten der Mineralgerbung schien es ein gewagtes Stück, die „R o tl ed e r fabrikation" zum Gegenstande eines neuen gröBeren Werkes zu machen. Jos. Borgman unternahm es dennoch: „ein wirklich gutes lohgares Leder wird trotzalledem nicht gänzlich vom Markte verdrängt werden" - das war seine volle Überzeugung. Aber gut muß es seìn, um dem ohne Zweifel sich durch hervorragende Eigenschaften auszeichnenden Chromleder gegenüber Stand halten zu können. Und um den Männern der Praxis in ihrer schwierigen Lage zur Hilfe zu kommen, entschloB er sich, seine Erfahrungen und Kenntnisse in der gesamten Fabrikation lohgarer Leder in einem Werke niederzulegen, dessen Vollendung er leider aber nicht mehr erleben sollte.

Nachdem etwa vor Jahresfrist der erste Band „Di e Unterlederfabrikation" bereits erschienen ist, übergebe ich hiermit auch den zweiten Teil, "Die Oberlederfabrikation", der Offentlichkeit, so daB das Werk nunmehr vollständig vorliegt. Der erste Teil fand allseits eine recht freundliche Aufnahme; dieselbe wünsche ich auch dem zweiten.

Wenn die Herstellung dieses Bandes etwas längere Zeit in Anspruch nahm, als anfangs angenommen wurde, so ist dies auf die großen Schwierigkeiten zurückzuführen, die mit der Sichtung und der Vervollständigung des hinterlassenen Manuskriptes verbunden waren.

Das Buch ist das Werk zweier Praktiker und auch in erster Linie für die Praxis geschrieben. Alles Wissenschaftliche ist denn auch gänzlich vermieden. Von dem Standpunkte ausgehend, daB gerade beim praktischen Geschäftsmann Zeit Geld ist, sind auch alle weitschweifigen Erörterungen über mehr oder weniger bekannte Vorgänge und Verrichtungen vermieden. Es konnten viele Kapitel deshalb sehr kurz gefaßt werden, weil die betr. Vorgänge bei anderen Ledersorten bereits beschrieben waren. An den betr. Stellen 
ist auf die einschlägigen früheren Abschnitte verwiesen, außerdem aber findet man in den einleitenden Kapiteln über das Allgemeine der Vorarbeiten, die Rohware etc. alles Nähere.

Möge denn das Buch ein willkommener Ratgeber werden für alle diejenigen, die der alten soliden Gerberei treu geblieben sind!

Berlin-Frieden a u, im Mai 1905.

Oskar Krahner.

\section{Vorwort zur zweiten, durchgesehenen und vermehrten Auflage.}

Die Hauptveränderungen, welche die Oberlederfabrikation in den letzten Jahren durchgemacht hat, sind der fast abgeschlossene Übergang der Gerbeindustrie, also auch der Oberledergerbeindustrie, vom Handwerk zum industriellen Großbetriebe.

Die von Josef Borgman herausgegebenen Bücher mit ihren bis ins einzelne durchdachten und der Praxis entnommenen Ausführungen für den Handwėrker haben durch diesen Übergang der Lederindustrie zum Großbetriebe durchaus nicht an Wert verloren, sondern es ist strenge darauf zu halten, daß jeder, der sich mit der Lederbearbeitung befaßit, zunächst diesen alten handwerksmäßigen Betrieb van Grund aus kennen lernt und die in diesem Buche gegebenen Anweisungen genau befolgen lernt, selbst wenn im Grobbetriebe diese Verfahren sich bedeutend vereinfacht haben sollten.

Wie jeder Organismus in abgekürzter Reihenfolge die früheren Entwicklungsstufen wiederholt, so müßte auch in der Industrie jeder darin praktisch Tätige zunächst das frühere Handwerk von Grund aus kennen gelernt haben. Wenn jetzt etwa 75 Prozent aller Oberleder nach dem Mineralgerbeverfahren hergestellt werden, so verweist der Herausgeber bezüglich der Technik dieser Mineralgerbungen auf das im gleichen Verlage erscheinende Werk: „Die Eisenund Alaungerbung", in welchem die dahin gehörigen Angaben gebracht werden.

Bezüglich der Lohgerbung wird es wohl kaum möglich sein, präzisere und genauere Vorschriften zu bringen als sie in dem vorliegenden Werke von Borgman gebracht worden sind. 
Für große Teile der Erde ist die Pflanzengerbung noch immer ein sehr wichtiger Industriezweig, und bei den Vetkehrsschwierigkeiten und Wirren, welche die Zeit nach dem Weltkriege gebracht hat, wird in den verschiedensten Ländern auf die altbewährte Methode der Lohgerbung mit Vorteil wieder zurückgegriffen werden müssen.

Der Herausgeber entläBt das Buch in der sicheren Zuversicht. daB diejenigen, welche nach den gebrachten Vorschriften arbeiten, gute Resultate $\mathrm{zu}$ verzeichnen haben werden.

Berlin, Februar 1923.

Prof. Dr. Hans Friedenthal. 